\title{
Age differences in the influence of metrical structure on phonetic identification
}

\author{
Shari R. Baum \\ School of Communication Sciences \& Disorders, McGill University, 1266 Pine Avenue West, Montréal, QC, Canada H3G 1 A8
}

Received 1 February 2001; received in revised form 1 December 2001; accepted 18 December 2001

\begin{abstract}
Two phonetic identification experiments were conducted with two groups of participants: a young adult group and an older adult group. In Experiment 1, subjects were required to make voiced-voiceless decisions for initial alveolar stop consonants to stimuli along two voice onset time (VOT) continua - one ranging from "di'gress" to "ti'gress" and the other from "digress" to "tigress" (i.e., in one continuum, the voiced endpoint was consistent with the word's stress pattern while in the other continuum, the voiceless endpoint was consistent with the word's stress pattern). Results revealed that both groups of participants were influenced by the stress pattern of the stimuli, but stress seemed to override VOT cues for a large number of the older individuals. To confirm that the effect was not simply due to a lexical influence, a follow-up experiment utilized two word-nonword continua ("diamond-tiamond" and "diming-timing") to examine the magnitude of lexical effects in these subject groups. Typical lexical status effects emerged for both young and older adults which were smaller than the effects of stress pattern found in Experiment 1. The findings are discussed with respect to the role of prosodic context in language processing in aging.
\end{abstract}

(c) 2002 Elsevier Science B.V. All rights reserved.

Keywords: Speech perception; Aging; Phonetic identification; Lexical stress

\section{Introduction}

Numerous investigations have addressed the issue of an age-related decline in spoken language processing abilities (e.g., Humes et al., 1994; Sommers and Danielson, 1999; Stine and Wingfield, 1994; Stine-Morrow et al., 1999; Tun et al., 1991; van Rooij and Plomp, 1990, 1992; Wingfield et al., 1989, 1991, 1992). Beyond the effects of age-related peripheral hearing loss or presbycusis (e.g., Schneider and Hamstra, 1999; Snell, 1997; Strouse et al., 1998; van Rooij and Plomp, 1990, 1992 among

E-mail address: shari.baum@mcgill.ca (S.R. Baum). many others), evidence suggests that speech perception and auditory word recognition skills may be affected by general cognitive slowing (Salthouse, 1988) and working memory constraints (Wingfield, 1996) associated with aging. Additional research has demonstrated an increased reliance on contextual information in language processing in elderly individuals (e.g., Cohen and Faulkner, 1983; but cf. Craik, 1968; Stine-Morrow et al., 1999). In fact, some have suggested that elderly listeners may utilize contextual cues to partially compensate for the decline in speech processing abilities (e.g., Boothroyd and Nittrouer, 1988; Pichora-Fuller et al., 1995; Sommers and Danielson, 1999; Wingfield, 1996, 1991). In addition to 
the effects of supporting semantic context, another type of contextual cue that has been examined in aging is prosodic information (e.g., Cohen and Faulkner, 1986; Wingfield et al., 1989, 1992). In particular, Cohen and Faulkner (1986) examined whether the imposition of exaggerated focal stress on words within a paragraph would differentially influence the text comprehension abilities of older and younger subjects. Results revealed that older individuals benefited more than did young subjects from the presence of appropriate focal stress in understanding and recalling spoken text passages.

In an investigation of a different nature, Wingfield et al. (1989) also explored whether older individuals would demonstrate a differential reliance on prosodic cues relative to young listeners. Using a sentence recall task with subject-defined recall intervals (i.e., the subjects decided at what point in the sentences to pause for recall), the investigators manipulated the presence or absence of normal sentential prosody in the stimuli. The findings showed that both older and younger adults were able to recall longer segments when normal prosodic cues were available. Interestingly, in contrast to young subjects whose recall accuracy was near ceiling in all conditions, the older listeners exhibited a decrement in recall performance in the absence of normal prosodic information. In a follow-up study, Wingfield et al. (1992) investigated sentence recall using stimuli containing major clause boundaries normally signaled by prosodic cues. The researchers manipulated the stimuli such that the sentences contained either matching or conflicting prosody (i.e., the prosodic cues to the clause boundaries matched or conflicted with the syntactic cues signaling a clause boundary). The results again suggested an increased reliance on prosody in the elderly subjects, reflected in a differentially increased error rate on sentences in which prosody and syntax conflicted. Moreover, the elderly subjects were more apt to alter the sentences in recall to render them consistent with the prosodic cues, rather than the syntactic (and/or semantic) content. These data suggest that older adults may not only rely on prosody more than young adults in language processing, but that they may use it as a primary cue, perhaps overriding other aspects of linguistic input (particularly if that input is somewhat impoverished for any reason).

Given these findings, it would be interesting to determine whether prosodic information differentially influences aspects of language processing in aging other than sentence recall or text comprehension. As a first step, it would be of particular interest to investigate the role of prosodic (metrical) structure on (low-level) phonetic identification which represents an initial stage of auditory language processing. The present study was designed with the goal of examining whether lexical stress patterns differentially influence phonetic decisions as a consequence of aging.

Many investigations have demonstrated that speech perception is a highly interactive process and that numerous contextual factors may affect phonetic perception (e.g., Elman and McClelland, 1986; Ganong, 1980; Samuel, 1986; Warren, 1970). In particular, it has been suggested that context may be relied upon most heavily when the acoustic-phonetic input is unclear or ambiguous (Burton et al., 1989; McQueen, 1991). In young adult subjects, it has been shown that lexical stress pattern can bias ambiguous voiced-voiceless stop consonant identification decisions. That is, Connine (1986) and Connine and Clifton (1987) created two voicing continua by manipulating voice onset time (VOT) in the initial stop consonants of the words "di'gress" and "ti'gress". The stimuli on both continua had identical VOT values, but one continuum contained the remainder of the word "digress" (i.e., from the vowel of the unstressed first syllable onward) and the other contained the remainder of the word "tigress" (i.e., from the vowel of the stressed first syllable onward). Subjects' identification of initial consonant voicing for stimuli in the ambiguous boundary region of the continuum was altered depending on the metrical stress pattern of the remainder of the word. In other words, the category boundary shifted across the two continua, in keeping with stress-consistent identification responses. Given these findings, and the proposal that elderly individuals may rely more on prosodic context in sentence comprehension tasks than young adults, one may hypothesize that older individuals will show a stronger lexical stress effect in a phonetic identifi- 
cation task as well. An increased reliance on prosodic context at this low level of language processing could have implications for all higher levels of language comprehension as well. Following Connine (1986) and Connine and Clifton (1987), the present investigation thus compared phonetic categorization along two alveolar stop voicing continua in groups of young and older adults.

\section{Experiment 1}

\subsection{Method}

\subsubsection{Subjects}

Two groups of participants were included in the study: a young adult group $(n=25)$ with a mean age of 24 years (range 18-31 years) and an older adult group $(n=25)$ with a mean age of 70 years (range 57-90 years). Groups were matched as closely as possible for education (within three years; education should have little influence on low-level phonetic identification abilities), and all older participants were screened for gross cognitive abilities (Mini-Mental Status Examination; Folstein et al., 1975) and for hearing within normal limits for the speech frequencies $(0.5,1$ and 2 $\mathrm{kHz}$ ). Both groups of subjects exhibited no history of speech, language, or hearing impairment according to self-report. Table 1 presents background information on the participants.

\subsubsection{Stimuli}

Two voiced-voiceless alveolar stop continua were created as follows. Ten repetitions of the

Table 1

Background information on young and older adult participants

\begin{tabular}{|c|c|c|c|c|c|c|c|c|}
\hline \multicolumn{4}{|c|}{ Young adults } & \multicolumn{4}{|c|}{ Older adults } & \multirow[b]{2}{*}{ MMSE } \\
\hline Subject & $\begin{array}{l}\text { Age } \\
\text { (in years) }\end{array}$ & $\begin{array}{l}\text { Education } \\
\text { (in years) }\end{array}$ & Sex & Subject & $\begin{array}{l}\text { Age } \\
\text { (in years) }\end{array}$ & $\begin{array}{l}\text { Education } \\
\text { (in years) }\end{array}$ & Sex & \\
\hline 1 & 29 & 18 & $\mathrm{~F}$ & 1 & 65 & 16 & $\mathrm{~F}$ & N/A \\
\hline 2 & 22 & 16 & $\mathrm{~F}$ & 2 & 67 & 10 & M & 26 \\
\hline 3 & 22 & 16 & $\mathrm{~F}$ & 3 & 75 & 8 & $\mathrm{~F}$ & 30 \\
\hline 4 & 25 & 15 & M & 4 & 62 & 11 & M & 29 \\
\hline 5 & 30 & 18 & M & 5 & 66 & 9 & M & 29 \\
\hline 6 & 25 & 16 & $\mathrm{~F}$ & 6 & 70 & 9 & M & 28 \\
\hline 7 & 29 & 15 & $\mathrm{~F}$ & 7 & 70 & 9 & M & N/A \\
\hline 8 & 30 & 14 & M & 8 & 66 & 12 & $\mathrm{~F}$ & 30 \\
\hline 9 & 31 & 18 & $\mathrm{~F}$ & 9 & 71 & 12 & $\mathrm{~F}$ & 27 \\
\hline 10 & 27 & 13 & $\mathrm{M}$ & 10 & 73 & 15 & M & 29 \\
\hline 11 & 27 & 14 & $\mathrm{~F}$ & 11 & 68 & 11 & $\mathrm{~F}$ & N/A \\
\hline 12 & 21 & 14 & M & 12 & 67 & 13 & $\mathrm{~F}$ & 30 \\
\hline 13 & 24 & 11 & $\mathrm{~F}$ & 13 & 63 & 13 & $\mathrm{~F}$ & 29 \\
\hline 14 & 28 & 14 & $\mathrm{~F}$ & 14 & 72 & 11 & $\mathrm{~F}$ & 30 \\
\hline 15 & 28 & 14 & $\mathrm{~F}$ & 15 & 90 & 7 & $\mathrm{~F}$ & 28 \\
\hline 16 & 24 & 18 & $\mathrm{~F}$ & 16 & 62 & 18 & $\mathrm{~F}$ & 28 \\
\hline 17 & 22 & N/A & $\mathrm{F}$ & 17 & 69 & 9 & $\mathrm{M}$ & 25 \\
\hline 18 & 18 & 14 & $\mathrm{M}$ & 18 & 70 & 12 & $\mathrm{~F}$ & 27 \\
\hline 19 & 20 & 15 & M & 19 & 78 & 12 & $\mathrm{~F}$ & 27 \\
\hline 20 & 21 & 15 & $\mathrm{~F}$ & 20 & 73 & 14 & $\mathrm{M}$ & 29 \\
\hline 21 & 24 & 16 & $\mathrm{~F}$ & 21 & 85 & 10 & $\mathrm{M}$ & 27 \\
\hline 22 & 21 & 15 & $\mathrm{~F}$ & 22 & 71 & 11 & $\mathrm{~F}$ & 26 \\
\hline 23 & 23 & 16 & $\mathrm{~F}$ & 23 & 70 & 17.5 & $\mathrm{~F}$ & 29 \\
\hline 24 & 20 & 13 & $\mathrm{~F}$ & 24 & 57 & 11 & $\mathrm{M}$ & 29 \\
\hline 25 & 21 & 15 & $\mathrm{~F}$ & 25 & 58 & 17 & $\mathrm{M}$ & 29 \\
\hline$\overline{\mathrm{x}}$ & 24 & 15 & & & 70 & 12 & & \\
\hline sd & 4 & 2 & & & 7 & 3 & & \\
\hline
\end{tabular}

${ }^{*}$ Score (out of 30) on Mini-Mental State Examination (Folstein et al., 1975). 
words "digress" and "tigress" (Connine, 1986; Connine and Clifton, 1987) were recorded by an adult male native speaker of English and digitized at a rate of $20 \mathrm{k}$ samples/s with a $9 \mathrm{kHz}$ low-pass filter and 12-bit quantization using the BLISS speech analysis system (Mertus, 1989). VOT values were computed for each token and based on these values, one representative exemplar of each word was selected for use as an endpoint stimulus. The chosen voiced endpoint had a VOT of $10.75 \mathrm{~ms}$, whereas the voiceless endpoint had a VOT of 45.65 $\mathrm{ms}$. The steps along the continuum differed by approximately $5 \mathrm{~ms}$ in VOT and were created by editing the natural speech tokens in the following manner. The burst and aspiration (if any) were excised from both original word productions, leaving "i'gress" and "igress". " For the voiced endpoint stimuli on both continua, the burst from

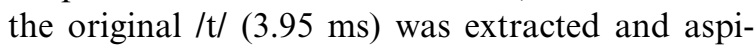
ration noise was added from the end of the original aspiration (to ensure a smooth transition into the upcoming vowel) to create a $10.75 \mathrm{~ms}$ VOT; this segment was then appended to both word endings to form "di'gress" and "'digress" (see Fig. 1). Each stimulus step was created in an analogous fashion, adding approximately $5 \mathrm{~ms}$ measuring from the end of the aspiration noise to produce eight steps. Thus, each step included the same burst and increasing amounts of aspiration noise. The VOT increment for the last step along the continuum was slightly shorter, at $4.9 \mathrm{~ms}$ to match the VOT of the original "tigress" stimulus. Although using this procedure entails increasing overall stimulus length across the continua, it was necessary to ensure that the stress cues carried in the relative vowel durations of the stimuli were maintained. Table 2 presents the VOT values and step sizes for each step along the continua.

\footnotetext{
${ }^{1}$ The stress contrasts were signalled primarily by duration differences across the syllables; the initial vowel of "i'gress" was $137 \mathrm{~ms}$ and the final vowel was $208 \mathrm{~ms}$. For "'igress", the initial vowel was $134 \mathrm{~ms}$ and the final vowel, $123 \mathrm{~ms}$. Fundamental frequency and amplitude were relatively constant across the syllables
}

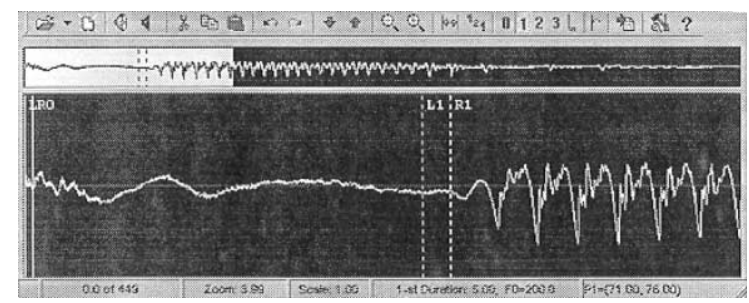

Fig. 1. Sample waveform illustrating VOT manipulation. L0 and R0 cursors mark /t/ burst. L1 and R1 cursors mark $5 \mathrm{~ms}$ segment of aspiration.

Table 2

VOT values and step sizes (in ms) of stimuli along the continua

\begin{tabular}{lll}
\hline Stimulus number & Voice onset time & Step size \\
\hline 1 & 10.75 & \\
2 & 15.75 & 5 \\
3 & 20.75 & 5 \\
4 & 25.75 & 5 \\
5 & 30.75 & 5 \\
6 & 35.75 & 5 \\
7 & 40.75 & 5 \\
8 & 45.65 & 4.9 \\
\hline
\end{tabular}

\subsubsection{Procedure}

Stimuli from both continua were presented to listeners binaurally over closed headphones at a comfortable level using BLISS software (Mertus, 1989). Each stimulus was presented ten times in random order for a total of 160 tokens. A $5 \mathrm{~s}$ interval separated the stimuli, during which listeners were required to decide whether the initial sound represented a /d/ or a /t/. They were not informed as to the identity of the endpoints. Subjects indicated their response by pressing a button labeled " $\mathrm{d}$ " or " $\mathrm{t}$ " on a response board, using their dominant hand only. Buttons were counterbalanced across subjects within each group. Responses were recorded by the computer.

\subsection{Results}

To examine whether metrical stress pattern influenced phonetic identification decisions, the percentage of voiced responses was computed for each listener at each step along the two continua. 
Category boundaries (50\% crossover points) were then calculated from these data by fitting a linear regression line to the data in the boundary regions (following Miller and Dexter, 1988). Boundaries could only be computed if labeling shifts occurred; the criteria established for boundary computation included a shift from at least $80 \%$ voiced responses to less than $30 \%$ voiced responses across the continuum. Overall percentage voiced responses was also calculated for each subject to examine perceptual shifts across the entire continuum.

Fig. 2 displays the mean identification functions for the younger and older subject groups separately. It should be noted that these graphs reflect data from 17 of the 25 young subjects and only 7 of
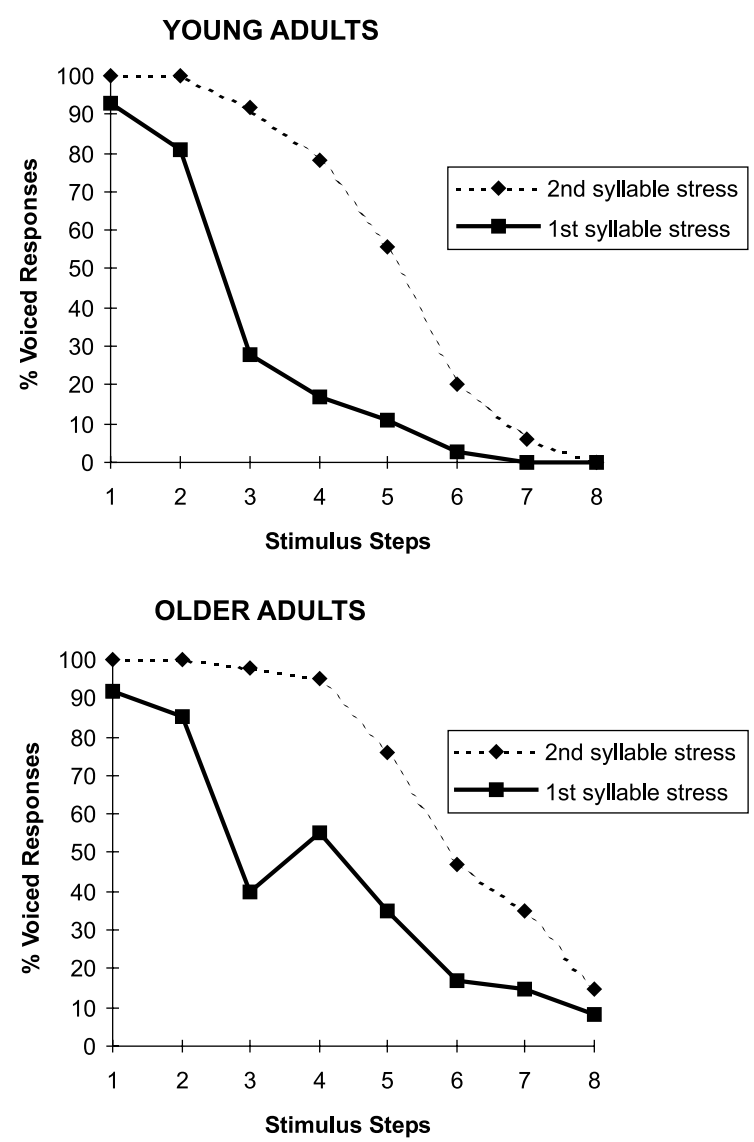

Fig. 2. Mean identification functions for old and younger groups on both continua on Experiment 1. (The data are based on 17 of the 25 young adults and 7 of the 25 older adults.) the 25 older adults for whom crossover boundaries could be computed. (This issue will be addressed in further detail below.) As may be seen, the boundary shifts were quite large and of comparable magnitude across the groups, at $11.68 \mathrm{~ms}$ for the young adults and $10.32 \mathrm{~ms}$ for the older adults. The category boundaries were submitted to a Group x Continuum analysis of variance (ANOVA) with repeated measures on the latter variable. The ANOVA revealed significant main effects of both Group $(F(1,22)=14.13, p<0.001)$ and Continuum $(F(1,22)=47.995, p<0.001)$, but no interaction. The main effect for Group was due to the average boundary values being somewhat higher for the older subjects (see also Boyczuk and Baum, 1999a).

Perhaps even more interesting was the finding that a large number $(n=18)$ of the older subjects were so strongly influenced by the metrical context that their percepts of even the endpoint stimuli were in keeping with the stress pattern rather than the actual VOT cues. Fig. 3 illustrates this pattern of identification functions for two typical older subjects within this large subgroup. Seven of the young listeners also displayed identification responses which precluded computation of crossover boundary values. Although evident, the influence of metrical context for these subjects was not quite as strong as that shown for the older adults, as illustrated in Fig. 4.

Analysis of the overall percentage of voiced responses included all subjects in each group. The mean values across the groups are displayed graphically in Fig. 5. It is clear that both groups showed far fewer voiced responses across the steps of the continua in the context of first syllable stress; the difference was most dramatic for the older subject group. A Group x Continuum ANOVA again revealed main effects of Group $(F(1$, $48)=5.203, p<0.05)$ and Continuum $(F(1$, $48)=200.488, p<0.001)$ and a Group $\times$ Continuum interaction $(F(1,48)=7.441, p<0.01)$, confirming the patterns shown in the graphs. Post hoc analysis of the interaction using the Newman-Keuls procedure $(p<0.01)$ revealed a significantly higher percentage of voiced responses in the context of second syllable stress for both groups. 
SUBJECT 2
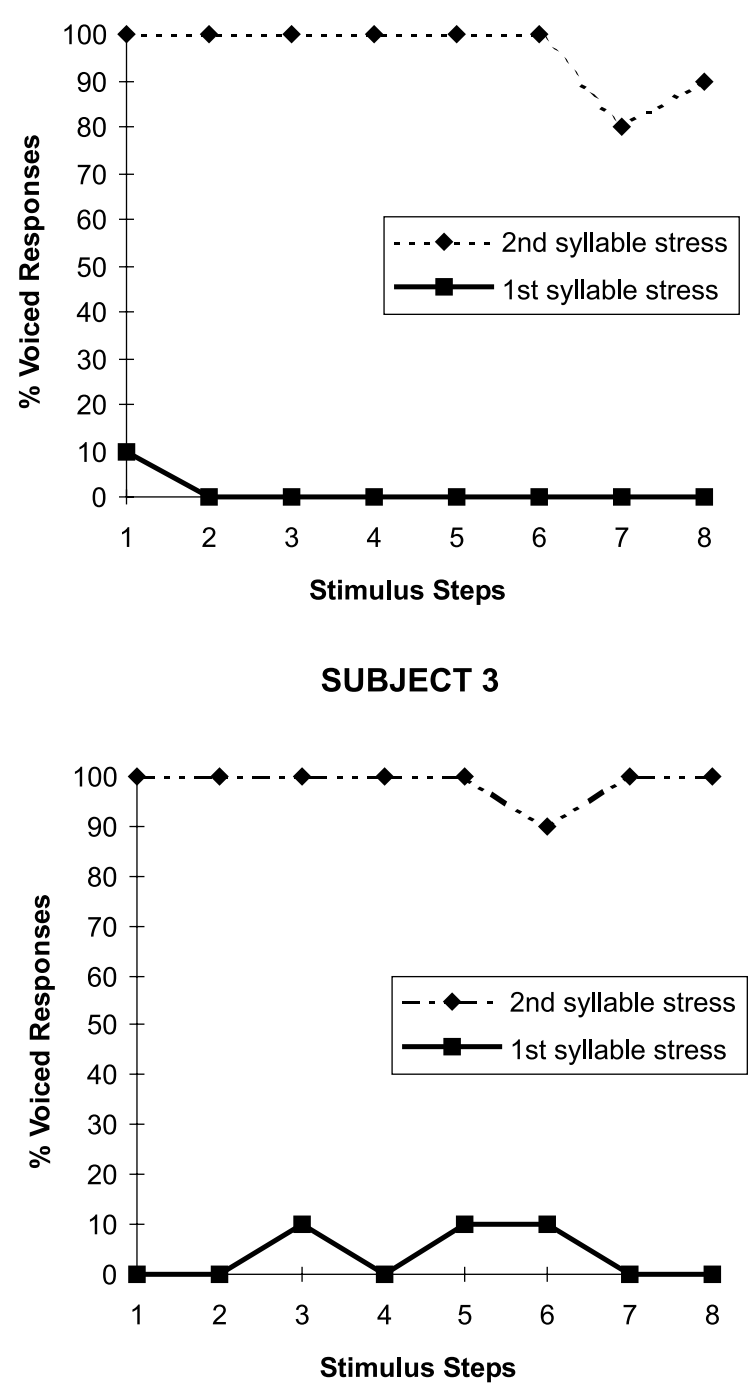

Fig. 3. Identification functions for two individual older adults illustrating stress-based phonetic decisions in Experiment 1.

\section{Discussion}

The main objective of the present experiment was to examine the degree to which older and young adult listeners would be influenced by the metrical properties of a word in making phonetic identification decisions. In particular, we hypothesized that older listeners would demonstrate an increased influence of prosodic context, in keeping
SUBJECT 6

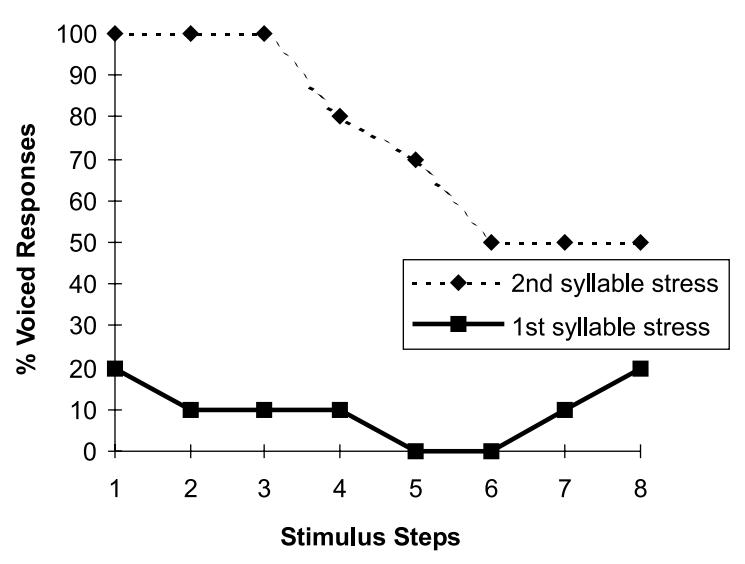

SUBJECT 8

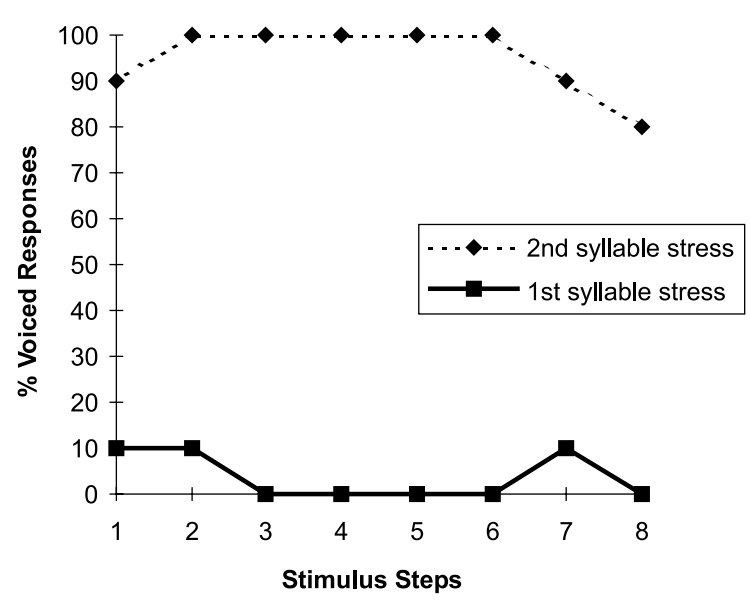

Fig. 4. Identification functions for two individual young adults illustrating stress-based phonetic decisions in Experiment 1.

with previous results from other domains of language processing (e.g., Cohen and Faulkner, 1986; Wingfield et al., 1989, 1992). The findings of the current experiment revealed that both groups of participants were influenced by lexical stress pattern in rendering stop consonant voicing categorization decisions, as reflected in a shift in the voiced-voiceless category boundary across the two continua and in percentage voiced responses across the continua. Notably, for many of the older listeners, phonetic identification responses were influenced by the prosodic context, overriding the 


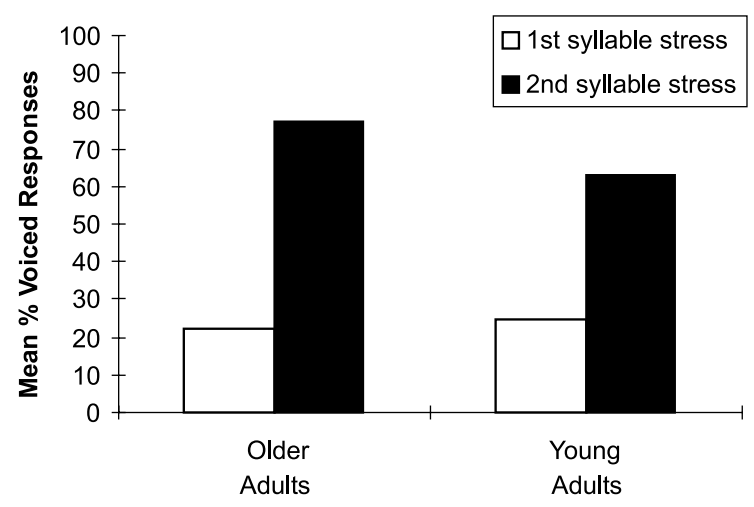

Subject Group

Fig. 5. Mean percent voiced responses across all stimuli of the continua for each group in Experiment 1.

VOT cues provided even in the unambiguous (with respect to VOT) endpoint stimuli of the continua. These results suggest that not only were older individuals able to make good use of context in this task (e.g., Sommers and Danielson, 1999; Wingfield et al., 1989), but that in fact they tended to exhibit an increased reliance on prosodic cues, perhaps even utilizing them as primary parameters in this speech perception task (see also Wingfield et al., 1992). As noted in the introduction, it has been suggested that elderly listeners may rely to a greater extent than young subjects on contextual cues to compensate, in part, for a decline in speech and language processing skills (including reductions in auditory acuity; e.g., Boothroyd and Nittrouer, 1988; Pichora-Fuller et al., 1995; Sommers and Danielson, 1999; Wingfield, 1996; Wingfield et al., 1991). A similar explanation has been proposed for speech processing in certain brain-damaged aphasic patients (Blumstein et al., 1994; Boyczuk and Baum, 1999b; see also Caplan and Aydelott-Utman, 1994). That is, nonfluent aphasic patients have been shown to exhibit larger-thannormal lexical effects in phonetic identification, attributed to a strategy invoked to compensate for phonetic processing impairments (Blumstein et al., 1994). Even in young normal listeners, contextual influences are most likely to emerge when the acoustic-phonetic input is somewhat degraded or ambiguous (Burton et al., 1989; McQueen, 1991). The results of the present investigation are in keeping with the interpretation that older individuals may compensate for low-level acousticphonetic processing difficulties by differentially relying on contextual support. Whether this increased reliance on context is a heuristic strategy or whether increased interaction simply emerges naturally as a consequence of degraded or "noisy" input remains to be resolved.

An additional related issue merits attention. One might question whether the contextual influence shown in the present investigation is truly an effect of stress pattern (i.e., prosody) or whether it may be attributable to an effect of lexical statusthat is, whether one endpoint stimulus is interpreted as a real word (and the other a non-word) and consequently favoured in identification. At least two factors mitigate against a lexical interpretation of this context effect. First, the magnitude of lexical effects on phonetic identification reported in previous studies (especially for alveolar stop voicing continua) is substantially smaller than the effect demonstrated in the present experiment (e.g., Burton et al., 1989; Fox, 1984; Ganong, 1980; Pitt and Samuel, 1993). Second, the fact that previous investigations have demonstrated an increased reliance on prosody in elderly listeners (e.g., Wingfield et al., 1992) supports a prosodic interpretation of the current findings as well. However, to ensure that a prosodic effect emerges over and above any lexical influence, a follow-up experiment was conducted to compare the magnitude of the boundary shifts due to a strictly lexical effect with those found in the present experiment.

\section{Experiment 2}

In an effort to confirm that the findings of Experiment 1 were indeed a function of prosodic (metrical) context and not simply lexical status, a second experiment was conducted to determine the pattern and magnitude of lexical effects in this population. To ensure that the effects found in Experiment 1 were not a result of peculiarities of the stimulus creation procedure, the continua for Experiment 2 were created using the same onsets (stop consonant VOTs) as in the previous experiment. 


\subsection{Method}

\subsubsection{Subjects}

The same two groups of individuals participated in Experiment 2, with a number of exceptions. Within the younger adult group, 7 of the original 25 listeners had to be replaced with new subjects. Within the older adult group, only 3 individuals were unavailable for follow-up testing, as shown in Table 3, which presents background information for the new participants, numbered according to the original subjects they replaced (see Table 1).

\subsubsection{Stimuli}

Two voiced-voiceless alveolar stop continua were created with word and non-word endpoints corresponding to the voiced ("diamond") and voiceless ("tiamond") or voiceless ("timing") and voiced ("diming") endpoints. The selected stimuli were bisyllabic, with the same vowel following the initial stop as in Experiment 1. Multiple repetitions of the words "diamond" and "timing" (which are approximately matched in frequency (Francis and Kucera, 1982)) were recorded by the same speaker as in Experiment 1, digitized at a rate of $20 \mathrm{k}$ samples/s with a $9 \mathrm{kHz}$ low-pass filter and 12-bit quantization, and the clearest token of each was identified for editing. The burst and aspiration were excised from both word tokens, leaving "iamond" and "iming". Next, the onsets (burst plus aspiration) from the "digress-tigress" continua (of Experiment 1) were appended to the word endings to create two 8-step continua with precisely the same onset characteristics as in Experiment 1 (see Table 2 for VOT values and step sizes).

\subsubsection{Procedure}

The procedure was the same as in Experiment 1.

\subsection{Results}

As in Experiment 1, to examine whether lexical status affected phonetic identification, the percentage of voiced responses was computed for each listener at each step along the two continua. Category boundaries and overall percentage voiced responses were calculated.

Fig. 6 illustrates the mean identification functions for the younger and older subject groups separately. As in Experiment 1, several subjects from each group produced response patterns that precluded boundary calculation; therefore, the graphs represent data from 18 of 25 young adults and 11 of 25 older adults. The boundary shifts are much smaller than in Experiment 1, with shifts of $3.79 \mathrm{~ms}$ for the young adults and $4.82 \mathrm{~ms}$ for the older adults. A Group x Continuum ANOVA on the boundary values yielded a main effect of Continuum $(F(1,26)=5.956, p<0.05)$, with no other effects emerging.

As in the first experiment, a number of the older subjects $(n=10)$ were strongly influenced by the (lexical) context of the stimuli, rendering phonetic decisions in keeping with lexical status even for the endpoint stimuli. Three young adults exhibited a similarly strong lexical bias, overriding the VOT cues even for the endpoint stimuli. The other

Table 3

Background information on new participants (replacements) in Expt. 2

\begin{tabular}{|c|c|c|c|c|c|c|c|c|}
\hline \multicolumn{4}{|c|}{ Young adults } & \multicolumn{4}{|c|}{ Older adults } & \multirow[b]{2}{*}{ MMSE* $^{*}$} \\
\hline Subject & $\begin{array}{l}\text { Age } \\
\text { (in years) }\end{array}$ & $\begin{array}{l}\text { Education } \\
\text { (in years) }\end{array}$ & Sex & Subject & $\begin{array}{l}\text { Age } \\
\text { (in years) }\end{array}$ & $\begin{array}{l}\text { Education } \\
\text { (in years) }\end{array}$ & Sex & \\
\hline 1 & 23 & 17 & $\mathrm{~F}$ & 1 & 73 & 16 & $\mathrm{~F}$ & 25 \\
\hline 2 & 27 & 18 & M & 7 & 68 & 9 & M & N/A \\
\hline 9 & 25 & 17 & $\mathrm{~F}$ & 11 & 59 & 11 & $\mathrm{~F}$ & 28 \\
\hline 10 & 24 & 18 & M & & & & & \\
\hline 11 & 22 & 17 & $\mathrm{~F}$ & & & & & \\
\hline 14 & 22 & 15 & $\mathrm{~F}$ & & & & & \\
\hline 15 & 25 & 14 & M & & & & & \\
\hline
\end{tabular}

${ }^{*}$ Score (out of 30) on Mini-Mental State Examination (Folstein et al., 1975). 
subjects for whom boundaries could not be calculated displayed mixed patterns across the continua, often exhibiting a voiced or voiceless response bias across both continua. ${ }^{2}$

Mean values for overall percentage of voiced responses (for all subjects in each group) are displayed in Fig. 7. Both groups showed a greater percentage of voiced responses for the 'diamondtiamond' continuum, consistent with a lexical effect, although again the difference was larger for the older listeners. A Group x Continuum ANOVA on these values yielded a trend toward a main effect of Group $(F(1,48)=3.705, p=0.06)$, a main effect of Continuum $(F(1,48)=28.332$, $<0.001)$, and a Group x Continuum interaction $(F(1,48)=9.925, p<0.005)$. Post hoc analysis of the interaction revealed a significantly higher percentage of voiced responses for the "diamondtiamond" continuum only for the older group.

\subsection{Discussion}

The results of Experiment 2 revealed a typical effect of lexical context on phonetic identification for both young and older adults, as reflected in boundary values, and in percentage of voiced responses across the entire continua for the older individuals (Burton et al., 1989; Connine and Clifton, 1987; Fox, 1984; Ganong, 1980; Miller and Dexter, 1988). The magnitude of the boundary shift was somewhat larger in the older adults relative to the younger listeners. In fact, the shift of only $3.79 \mathrm{~ms}$ exhibited by the young adults is small, although not atypical for alveolar stop VOT continua (see Newman et al., 1999; Pitt and Samuel, 1993 for two different explanations of the reduction in lexical effects for alveolar stimuli).

\footnotetext{
${ }^{2}$ Whereas the endpoint stimuli were identified at an average of $>90 \%$ accuracy in a post-test, it remains possible that these stimuli were somewhat ambiguous as "anchors" and contributed to the inconsistency in responses, particularly to the apparent lexical effects for certain individuals at the continuum endpoints. It is a remote possibility that exposure to, or secondlanguage knowledge of French may have influenced the perceptual quality of the endpoint stimuli for some individuals, as voicing categories differ somewhat in Québec French and English.
}

YOUNG ADULTS
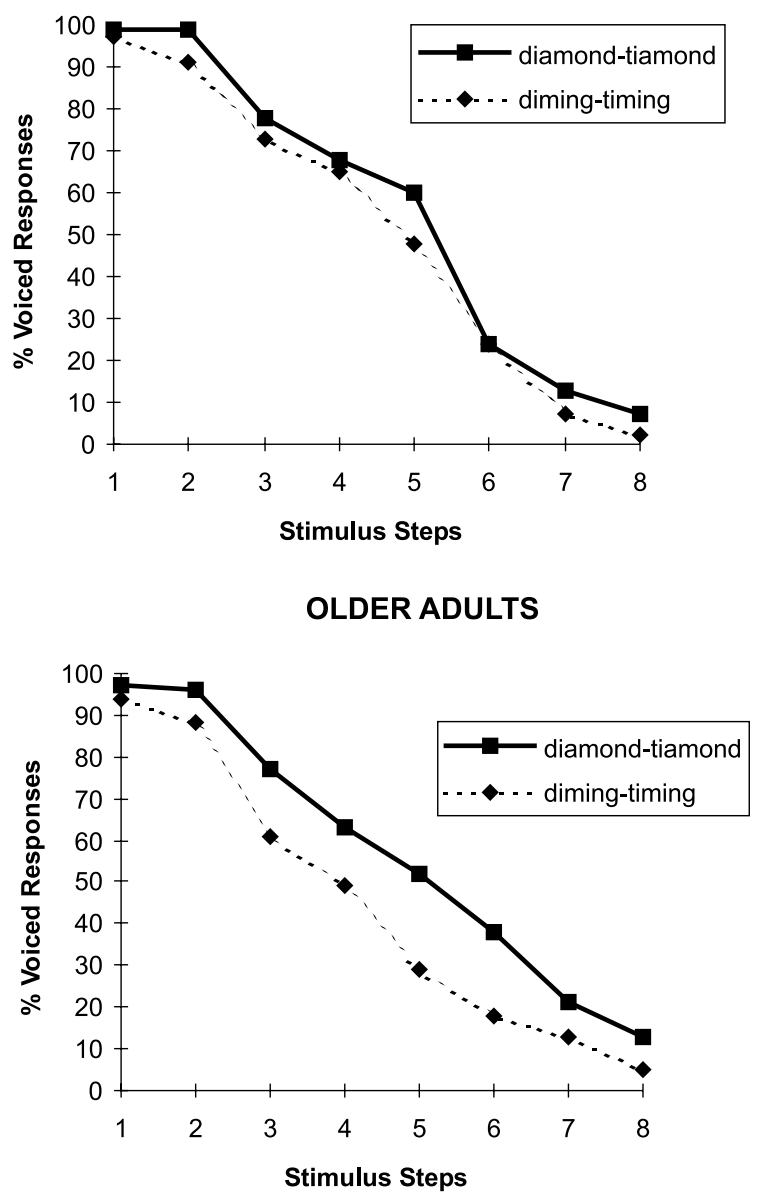

Fig. 6. Identification functions for young and older groups on both continua in Experiment 2. (The data are based on 18 of the 25 younger adults and 11 of the 25 older adults.)

While differences across groups emerged only for the percentage of voiced responses in the statistical analyses, as in Experiment 1, a larger number of older than young listeners were strongly biased by context, responding according to lexical status across all steps of the continua. (This number, however, was substantially smaller than in Experiment 1.) This pattern, in conjunction with the somewhat larger magnitude boundary shift in the older group, is consistent with an increased reliance on context in these individuals (Boothroyd and Nittrouer, 1988; Pichora-Fuller et al., 


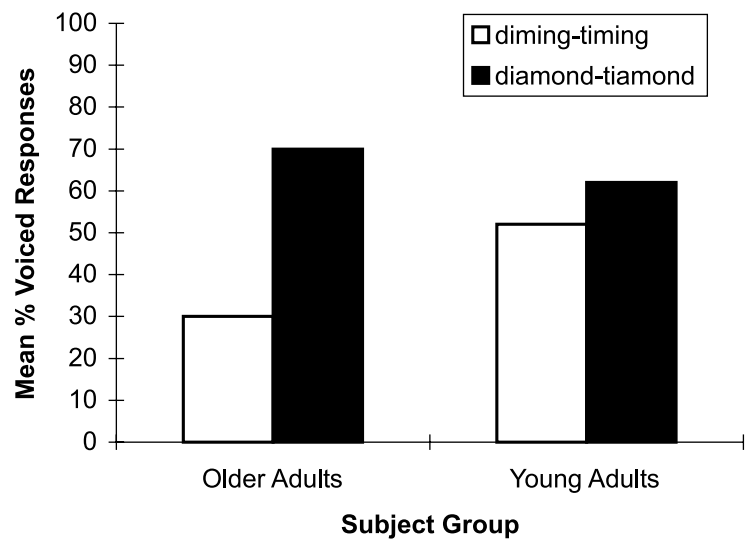

Fig. 7. Mean percent voiced responses across all stimuli of the continua for each group in Experiment 2.

1995; Sommers and Danielson, 1999; Wingfield, 1996; Wingfield et al., 1991).

\subsection{General discussion}

Experiment 2 was conducted as a follow-up study to confirm that the findings of Experiment 1 truly reflected the contribution of prosodic context over and above any lexical influence. The data from Experiments 1 and 2 were not directly compared statistically because a subset of the subjects in each group differed across experiments. However, in comparing the magnitude of the contextual influences, it is clear that the effect of metrical stress context (average boundary shift $=11.0 \mathrm{~ms}$; statistical effect size $\left(\mathfrak{n}_{\mathrm{p}}^{2}\right)=0.847$ ) was substantially larger than that of lexical status (average boundary shift $=4.31 \mathrm{~ms}$; effect size $\left(\mathrm{n}_{\mathrm{p}}^{2}\right)=0.186$ ) for both groups, despite the identical onsets used in both experiments. Thus, metrical stress appears to have a strong and independent influence on phonetic identification decisions (Connine and Clifton, 1987).

With respect to differences across the groups, as noted above, a much larger number of older individuals were completely biased by metrical context in Experiment $1(n=18)$ compared to lexical context in Experiment $2(n=10)$. Only a small number of young adults showed a similar bias and this number did not differ substantially across experiments. It is difficult to know to which set of results to attribute more weight-the similar identification functions across the groups (for those listeners for whom boundaries could be computed), or the rather dramatic difference in the number of older versus young listeners who were completely biased by metrical context. It appears that, as in much previous research on language processing in aging, there is a great deal of heterogeneity within the older adult group. The frequency with which a certain pattern emerges must be interpreted as a reflection of changes associated with aging which does not affect all individuals equivalently. One factor that may play a role in this heterogeneity is hearing acuity. Whereas all of the listeners in the present investigation passed an audiometric screening, it remains possible that individual differences in auditory sensitivity may have resulted in different strategies having been adopted by listeners (see e.g., Boothroyd and Nittrouer, 1988; Sommers and Danielson, 1999; Wingfield et al., 2000). Overall, it appears that while older individuals rely more on context than do young adults in general, they are particularly sensitive to prosodic patterns (see also Wingfield et al., 1992). The findings suggest that both lexical and prosodic context make independent contributions to phonetic identification in a large proportion of older listeners, with the influence of metrical stress proving to be quite strong.

In summary, the results of the present investigation are consistent with the hypothesis that, under conditions of increased stimulus uncertainty, elderly listeners make use of context - and prosodic context, in particular - to aid in phonetic identification, and further that they display a differential reliance on such contextual information relative to young adult listeners. Perhaps with competition for somewhat reduced processing resources associated with aging (Wingfield and Stine, 1989), the language processing system compensates by altering the perceptual weighting of certain speech perception cues or by adjusting the degree to which the subcomponents of the system interact. Language processing abilities may be quite robust to cognitive changes associated with aging (e.g., Meyer and Rice, 1981; Taub, 1979) because of the redundancy built into the system and/or because of elderly individuals' ability to 
make use of compensatory mechanisms and contextual information (Wingfield, 1996; Wingfield et al., 1989, 1992).

\section{Acknowledgements}

This work was supported by funds from the Medical Research Council of Canada and the Fonds FCAR du Québec. Thanks are due to Jeff Boyczuk and two anonymous reviewers for comments on an earlier version of this paper.

\section{References}

Blumstein, S., Burton, M., Baum, S., Waldstein, R., Katz, D., 1994. The role of lexical status on the phonetic categorization of speech in aphasia. Brain and Language 46, 181-197.

Boothroyd, A., Nittrouer, S., 1988. Mathematical treatment of context effects in phoneme and word recognition. J. Acoust. Soc. Amer. 84, 101-114.

Boyczuk, J., Baum, S., 1999a. Top-down influences on phonetic processing as a function of aging. J. Acoust. Soc. Amer. 105, 1402.

Boyczuk, J., Baum, S., 1999b. The influence of neighborhood density on phonetic categorization in aphasia. Brain Language $67,46-70$.

Burton, M., Baum, S., Blumstein, S., 1989. Lexical effects on the phonetic categorization of speech: The role of acoustic structure. J. Exper. Psychology: Human Perception and Perform. 15, 567-575.

Caplan, D., Aydelott-Utman, J., 1994. Selective acousticphonetic impairment and lexical access in an aphasic patient. J. Acoust. Soc. Amer. 95, 512-517.

Cohen, G., Faulkner, D., 1983. Word recognition: Age differences in contextual facilitation effects. Br. J. Psychology 74, 239-251.

Cohen, G., Faulkner, D., 1986. Does 'elderspeak' work? The effect of intonation and stress on comprehension and recall of spoken discourse in old age. Language Commun. 6, 9198.

Connine, C., 1986. Modularity and auditory word recognition. Unpublished doctoral dissertation, University of Massachusetts.

Connine, C., Clifton, C., 1987. Interactive use of lexical information in speech perception. J. Exper. Psychology: Human Perception Perform. 13, 291-299.

Craik, F., 1968. Short-term memory and the aging process. In: Talland, G. (Ed.), Human Aging and Behavior: Recent Advances in Research and Theory. Academic Press, New York.

Elman, J., McClelland, J., 1986. Exploiting lawful variability in the speech wave. In: Perkell, J., Klatt, D. (Eds.), Invariance and Variability in Speech Processes. Erlbaum Associates, Hillsdale, NJ.
Folstein, M., Folstein, S., McHugh, P., 1975. Mini-mental state: A practical method for grading the cognitive state of patients for the clinician. J. Psychiatry Res. 12, 189-198.

Fox, R., 1984. Effect of lexical status on phonetic categorization. J. Exper. Psychology: Human Perception Perform. 10, 526-540.

Ganong, W., 1980. Phonetic categorization in auditory word perception. J. Exper. Psychology: Human Perception Perform. 6, 110-125.

Humes, L., Watson, B., Christensen, L., Cokely, C., Halling, D., Lee, L., 1994. Factors associated with individual differences in clinical measures of speech recognition among the elderly. J. Speech Hearing Res. 37, 465-474.

McQueen, J., 1991. The influence of the lexicon on phonetic categorization: Stimulus quality in word-final ambiguity. J. Exper. Psychology: Human Perception Perform. 17, 433-443.

Mertus, J., 1989. BLISS user's manual. Providence, RI: Brown University.

Meyer, B., Rice, G., 1981. Information recalled from prose by young, middle, and old adult readers. Exper. Aging Res. 7, 253-268.

Miller, J., Dexter, E., 1988. Effects of speaking rate and lexical status on phonetic perception. J. Exper. Psychology: Human Perception Perform. 14, 369-378.

Newman, R., Sawusch, J., Luce, P., 1999. Underspecification and phoneme frequency in speech perception. In: Broe, M., Pierrehumbert, J. (Eds.), Papers in Laboratory Phonology V: Language Acquisition and the Lexicon. Cambridge University Press, Cambridge.

Pichora-Fuller, K., Schneider, B., Daneman, M., 1995. How young and old adults listen to and remember speech in noise. J. Acoust. Soc. Amer. 97, 593-608.

Pitt, M., Samuel, A., 1993. An empirical and meta-analytic evaluation of the phoneme identification task. J. Exper. Psychology: Human Perception Perform. 19, 699-725.

Salthouse, T., 1988. Effects of aging on verbal abilities. In: Light, L., Burke, D. (Eds.), Language, Memory and Aging. Cambridge University Press, New York.

Samuel, A., 1986. The role of the lexicon in speech perception. In: Schwab, E., Nusbaum, N. (Eds.), Pattern Recognition by Humans and Machines, Vol. 1, Speech Perception. Academic Press, Orlando, FL.

Schneider, B., Hamstra, S., 1999. Gap detection thresholds as a function of tonal duration for younger and older listeners. J. Acoust. Soc. Amer. 106, 371-380.

Snell, K., 1997. Age-related changes in temporal gap detection. J. Acoust. Soc. Amer. 101, 2214-2220.

Sommers, M., Danielson, S., 1999. Inhibitory processes and spoken word recognition in young and older adults: The interaction of lexical competition and semantic context. Psychology Aging 14, 458-472.

Stine, E., Wingfield, A., 1994. Older adults can inhibit highprobability competitors in speech recognition. Aging Cognition 1, 152-157.

Stine-Morrow, E., Miller, L., Nevin, J., 1999. The effects of context and feedback on age differences in spoken word recognition. J. Gerontology: Psychological Sci. B 54, P125-P134. 
Strouse, A., Ashmead, D., Ohde, R., Grantham, D.W., 1998. Temporal processing in the aging auditory system. J. Acoust. Soc. Amer. 104, 2385-2399.

Taub, H., 1979. Comprehension and memory of prose materials by young and old adults. Exper. Aging Res. 5, 3-13.

Tun, P., Wingfield, A., Stine, E., 1991. Speech processing capacity in young and older adults: A dual-task study. Psychology and Aging 6, 3-9.

van Rooij, J.C.G.M., Plomp, R., 1990. Auditive and cognitive factors in speech perception by elderly listeners. II. Multivariate analyses. J. Acoust. Soc. Amer. 88, 26112624.

van Rooij, J.C.G.M., Plomp, R., 1992. Auditive and cognitive factors in speech perception by elderly listeners. III. Additional data and final discussion. J. Acoust. Soc. Amer. 91, 1028-1033.

Warren, R., 1970. Perceptual restoration of missing speech sounds. Science 167, 392-395.

Wingfield, A., 1996. Cognitive factors in auditory performance: Context, speed of processing, and constraints of memory. J. Amer. Acad. Audiology 7, 175-182.
Wingfield, A., Stine, E., 1989. Modeling memory processes: Research and theory on memory and aging. In: Filmore, G., Whitehouse, P., Wykle, M. (Eds.), Memory Aging and Dementia: Theory, Assessment, and Treatment. Springer Verlag, New York.

Wingfield, A., Lahar, C., Stine, E., 1989. Age and decision strategies in running memory for speech: Effects of prosody and linguistic structure. J. Gerontology: Psychological Sci. 44, P106-P113.

Wingfield, A., Aberdeen, J., Stine, E., 1991. Word onset gating and linguistic context in spoken word recognition by young and elderly adults. J. Gerontology: Psychological Sci. 46, P127-P129.

Wingfield, A., Wayland, S., Stine, E., 1992. Adult age differences in the use of prosody for syntactic parsing and recall of spoken sentences. J. Gerontology: Psychological Sci. 47, P350-P356.

Wingfield, A., Lindfield, K., Goodglass, H., 2000. Effects of age and hearing sensitivity on the use of prosodic information in spoken word recognition. J. Speech, Language, Hearing Res. 43, 915-925. 